\title{
High resolution regional climate model simulations for Germany: Part II-projected climate changes
}

\author{
Sven Wagner • Peter Berg • Gerd Schädler • \\ Harald Kunstmann
}

Received: 19 October 2011/Accepted: 21 August 2012/Published online: 13 September 2012

(C) The Author(s) 2012. This article is published with open access at Springerlink.com

\begin{abstract}
The projected climate change signals of a five-member high resolution ensemble, based on two global climate models (GCMs: ECHAM5 and CCCma3) and two regional climate models (RCMs: CLM and WRF) are analysed in this paper (Part II of a two part paper). In Part I the performance of the models for the control period are presented. The RCMs use a two nest procedure over Europe and Germany with a final spatial resolution of $7 \mathrm{~km}$ to downscale the GCM simulations for the present (1971-2000) and future A1B scenario (2021-2050) time periods. The ensemble was extended by earlier simulations with the RCM REMO (driven by ECHAM5, two realisations) at a slightly coarser resolution. The climate change signals are evaluated and tested for significance for mean values and the seasonal cycles of temperature and precipitation, as well as for the intensity distribution of precipitation and the numbers of dry days and dry periods. All GCMs project a significant warming over Europe on seasonal and annual scales and the projected warming of the GCMs is retained in both nests of the RCMs, however, with added small variations. The mean warming over Germany
\end{abstract}

\author{
S. Wagner $(\bowtie) \cdot$ H. Kunstmann \\ Institute for Meteorology and Climate Research (IMK-IFU), \\ KIT, Kreuzeckbahnstraße 19, 82467 Garmisch-Partenkirchen, \\ Germany \\ e-mail: sven.wagner@kit.edu \\ P. Berg · G. Schädler \\ Institute for Meteorology and Climate Research (IMK-TRO), \\ KIT, Hermann-von-Helmholtz Platz 1, Bldg. 435, \\ 76344 Eggenstein-Leopoldshafen, Germany \\ Present Address: \\ P. Berg \\ Rossby Centre, SMHI, Folkborgsvägen 1, \\ 60176 Norrköpping, Sweden
}

of all ensemble members for the fine nest is in the range of 0.8 and $1.3 \mathrm{~K}$ with an average of $1.1 \mathrm{~K}$. For mean annual precipitation the climate change signal varies in the range of -2 to $9 \%$ over Germany within the ensemble. Changes in the number of wet days are projected in the range of $\pm 4 \%$ on the annual scale for the future time period. For the probability distribution of precipitation intensity, a decrease of lower intensities and an increase of moderate and higher intensities is projected by most ensemble members. For the mean values, the results indicate that the projected temperature change signal is caused mainly by the GCM and its initial condition (realisation), with little impact from the RCM. For precipitation, in addition, the RCM affects the climate change signal significantly.

Keywords Regional climate modeling - Ensemble · High resolution $7 \mathrm{~km}$. Precipitation - COSMO-CLM . WRF - Germany · Climate change - Significance test

\section{Introduction}

In the fourth assessment report (AR4) of the Intergovernmental Panel on Climate Change (IPCC) a global warming of about $0.2 \mathrm{~K}$ per decade for the twenty-first century is projected within the range of the SRES scenarios, with even larger increases for sub-regions, such as Europe (Christensen et al. 2007). For annual mean precipitation, an increase in most of Northern Europe and a decrease in most of the Mediterranean area are projected. For Central Europe, the AR4 GCM ensemble models show approximately equal projections of increases and decreases in annual mean precipitation, and weak signals. On seasonal scales, precipitation is likely to increase in winter in Northern and Central Europe, and to decrease in summer in Southern and 
Central Europe, but the models disagree on the magnitude and geographical details of the climate change signals. Thus, Central Europe is a region with large uncertainty for the mean state of future climate. In addition changes in the probability distribution of precipitation are projected (e.g. Frei et al. 2003; Boberg et al. 2009, 2010).

For many climate impact studies, simulation results of regional climate simulations are an essential input. In particular impact studies investigating climate changes of natural hazards require high resolution meteorological forcing data. One example is hydrological simulations for the assessment of flood hazards in a changing climate, in particular for smaller and medium sized catchments. The increase in horizontal resolution enables a more detailed model simulation which usually provides better simulation results in the presence of complex fine scale topographical features and in simulating extreme events (Giorgi 2006). Furthermore, a better performance of the simulated spatial patterns and intensity distributions of precipitation is achieved (Boberg et al. 2010).

The spatial resolution of RCM simulations has steadily increased over the last decades. For Europe, larger ensemble assessments of climate changes were carried out in the PRUDENCE project (Christensen and Christensen 2007) with a main resolution of around $50 \mathrm{~km}$ and the ENSEMBLES project (Hewitt 2005) with a spatial resolution of $25 \mathrm{~km}$. Even higher resolutions have been carried out, e.g. with the RCM CLM at around $18 \mathrm{~km}$ in the socalled consortium simulations (Feldmann et al. 2008), with the HIRHAM model at $12 \mathrm{~km}$ within the PRUDENCE project (Christensen and Christensen 2007), and with the REMO model at $10 \mathrm{~km}$ within the framework of UBA (Umweltbundesamt) and BFG (Bundesanstalt für Gewässerkunde) projects (Jacob et al. 2007b) covering the region of Germany. The PRUDENCE projections of changes in precipitation show a north-south gradient with positive changes in the north and negative changes in the south and a transition zone which moves with the season and varies between the models (Christensen and Christensen 2007). For temperature, an increase is projected for all seasons all over Europe with largest warming in summer in the Mediterranean region. The analysis showed higher geographic details in the fields modelled and a tendency for less warming compared to the coarser GCM simulations. Furthermore, they noted that regional models with quite different biases (Jacob et al. 2007a) are much closer to one another in simulating climate change. Déqué et al. (2007) assessed the uncertainties of the PRUDENCE regional climate simulations. They found that the role of the GCM is generally greater than the role of the RCM, but for summer precipitation the uncertainty introduced by the choice of the RCM is of the same magnitude as the choice of the GCM. Furthermore, Boberg et al. (2009, 2010) found a clear relative increase of more intense and decrease of light and moderate precipitation days contributing to total precipitation for the scenario periods.

We constructed a multi model ensemble of high resolution $7 \mathrm{~km}$ regional climate simulations for a present (1971-2000) and a near future (2021-2050) time period covering Germany and the near surroundings. Simulation periods are 1968-2000 and 2018-2050 which allows three years of spinup for each simulation. The ensemble is based on two GCMs (ECHAM5 and CCCma3) and two RCMs (CLM and WRF), and the simulations were performed within the CEDIM ${ }^{1}$ project "Flood hazard in a changing climate" to assess the climate change impact on medium and small sized river catchments in Germany (Schädler et al. 2012). By including multiple GCMs and RCMs and also three realisations (referred to as R1-3 in text and figures) of ECHAM5, the ensemble samples some of the uncertainty involved in future projections due to the models used as well as natural variability. In total, five high resolution simulations were performed, CLM for all 4 GCMs and WRF for ECHAM5 R1. This ensemble is the largest set of RCM simulations for Germany at such high horizontal resolution for two 30 year time periods. Furthermore, the ensemble includes to our knowledge the first long-term regional climate simulation of the RCM WRF for Central Europe. In addition, two earlier simulations carried out with the REMO model at $10 \mathrm{~km}$ resolution (Jacob et al. 2007b) are included for the analysis and comparison.

The near future time period 2021-2050 was chosen due to the scope of this project to investigate changes in flood hazard for a period which conforms with the planning horizons of water resource management systems. For this time period the projected climate change signal is minor compared to the last 30 years of the twenty-first century which is usually applied in studies investigating possible climate change. Furthermore, the choice of the emission scenario on the projected climate change signal is low for the near future time period.

In Part I (Berg et al. 2012) of this two part paper, the ensemble was validated with observational data. The validation results showed the benefit of bringing high detail in the spatial patterns, and added value to the precipitation intensity distribution, especially for extreme events, as also previously seen in e.g. Boberg et al. (2010) and Frei et al. (2003). In the current paper, Part II, climate projections for temperature and precipitation for a near future time period are investigated together with possible added value of higher spatial resolution.

The applied GCMs and RCMs are described briefly in Sect. 2. Section 3 presents a detailed analysis of the

\footnotetext{
${ }^{1}$ Center for Disaster Management and Risk Reduction Technology; http://www.cedim.de.
} 
projected change signals of the GCMs and both nests of the RCMs. The paper closes with a summary and conclusions in Sect. 4.

\section{Models}

The ensemble is based on two GCMs and two RCMs, which are described in detail in Part I of this study (Berg et al. 2012) and only the main features of the models are repeated here. The two GCMs (ECHAM5 and CCCma3) were selected based on their performance on a global scale (Reichler and Kim 2008) and on their availability. For the dynamical downscaling two state of the art, non-hydrostatic RCMs (CLM and WRF) were chosen. Due to the large step in horizontal resolution between the GCMs (200-300 km) and the target resolution of $7 \mathrm{~km}$, a double nesting approach is applied for each of the RCMs.

\subsection{GCMs}

The bulk of the simulations are carried out using the IPCC-AR4 simulations with the ECHAM5/MPIOM model system at T63 resolution (Roeckner et al. 2003). Three realisations, i.e. simulations with different initial conditions, of these simulations are used. In addition, one CLM simulation uses realisation four of the CCCma3 (Scinocca et al. 2008) at a T47 horizontal resolution. For both GCMs the responses to the IPCC SRES A1B forcing scenario are investigated in comparison to the twentieth century anthropogenic forcing only simulations.

\section{$2.2 \mathrm{RCMs}$}

The CLM model (version 4.8) uses a Runge-Kutta timestepping scheme, the radiation scheme of Ritter and Geleyn (1992) is called every hour, the Tiedtke (1989) scheme is used for convective mass flux parameterisation and the four species cloud scheme of Doms and Schättler (2002) provides prognostic precipitation.

The WRF-ARW model version 3.1.1 (Skamarock et al. 2008) uses the WSM5 microphysical parameterisation (Hong et al. 2004; Hong and Lim 2006), the modified version of the Kain-Fritsch scheme (Kain 2004) for cumulus parameterisation, the Noah land surface model (Chen and Dudhia 2001), the YSU PBL parameterisation (Hong et al. 2006), Dudhia shortwave (Dudhia 1989) and RRTM longwave (Mlawer et al. 1997) radiation scheme.

Both RCMs, CLM and WRF, follow a double nesting procedure with a coarse nest extending over all of Europe at around $50 \mathrm{~km}$ resolution, and the fine nest covering Germany and the near surroundings at $7 \mathrm{~km}$ resolution (see Fig. 1). Both models use 40 vertical levels for both nests.

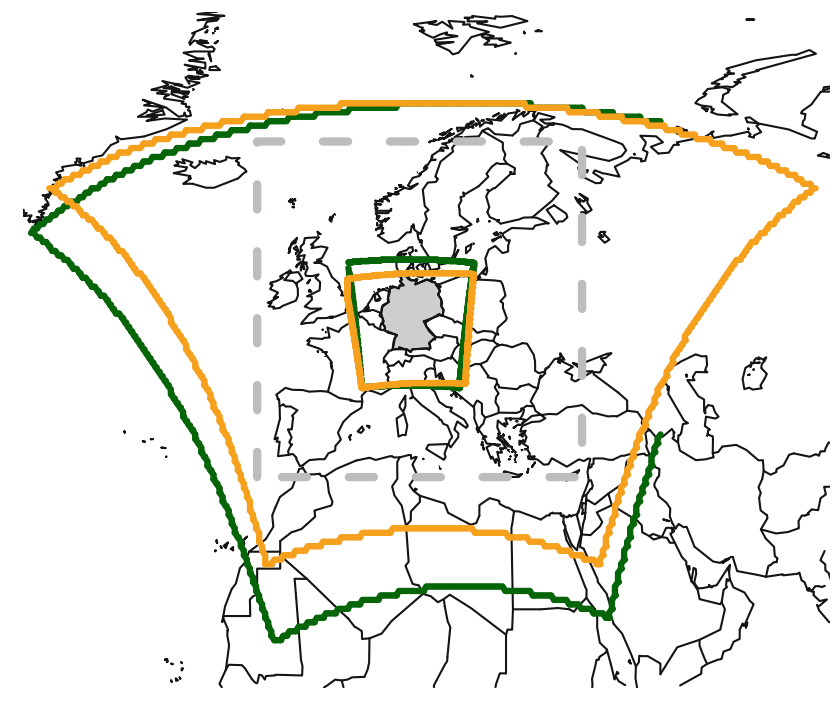

Fig. 1 Map of the simulation domains indicating the coarse and fine nests of CLM (green) and WRF (orange). The evaluation domain for the coarse nest is marked with a gray dashed rectangle. For the fine nest, the region of Germany (filled in gray) is used as evaluation domain

Results from previous simulations with the REMO model at a slightly coarser resolution are included in this study for comparison (Jacob et al. 2007b). The hydrostatic REMO model (Jacob et al. 2001) is based on the ECHAM4 physical package using radiation parameterisation of Morcrette et al. (1986), the Sundquist (1978) large-scale cloud parameterisation and the Tiedtke (1989) and Nordeng (1994) convective parameterisations. For the simulations for Germany, Jacob et al. (2007b) used a double nesting approach with a coarse nest of about $50 \mathrm{~km}$ and a fine nest of about $10 \mathrm{~km}$, both with 27 vertical levels to dynamically downscale realisation one and two of the ECHAM5 GCM simulations.

\section{Results}

For the analysis of projected climate change between the present (1971-2000) and near future A1B scenario (2021-2050) time periods, the same domains are used as for the validation process. The analysis comprises entire Europe for the GCMs and the coarse nests and the political region of Germany for the fine nest (see Fig. 1). For the direct comparison of the different simulations, each of the model grids were bilinearly interpolated to regular grids of $0.44^{\circ}$ for the coarse nest and $0.0625^{\circ}$ for the fine nest. Due to the close agreement between the original models grids and the regular grid, the interpolation does not affect the results significantly.

To investigate the evolution of the climate change signal and the corresponding uncertainties, the analysis includes 
the coarse resolution GCM and coarse nest RCM results. The focus of this paper is, however, on climate change projections for Germany of the high resolution fine nest simulations. To estimate the statistical significance of the climate change signals, Student's $t$ tests were performed, and presented with $95 \%$ confidence intervals in the figures. For the tests, annual means were used in order to have independent and identically distributed data. For temperature, the linear trend within the two 30-year time periods was first removed so that the time-series become stationary and the distributions remain normal. Before applying Student's $t$ test, the data were tested for normality. The test results showed that the assumption is fulfilled unless indicated otherwise. Due to the near future time period from 2021 to 2050 of this study the climate change projections of this ensemble can only be compared qualitatively to most previous results (e.g. IPCC-AR4 and PRUDENCE), which usually selected the last 30 years of the twenty-first century as future time period.

\subsection{GCM and coarse nest simulations}

The projected annual mean temperature changes over the coarse nest between the time slices 1971-2000 and 2021-2050 are shown in Fig. 2. All GCMs, the three realisations of ECHAM5 (in figures named E5R1-3) and the CCCma3 (C3), project a significant warming over Europe. The range of the areal average varies between 1.1 and $1.5 \mathrm{~K}$. Both the CLM and WRF downscaling simulations indicate a similar warming, however, with lower magnitudes in the range of 0.9 and $1.3 \mathrm{~K}$ for the areal average. No additional impact of the bias was found. On a seasonal scale an increase of mean temperature is present for all applied GCMs and RCMs (not shown). The warming in Northern and Central Europe is likely to be largest in winter. The projected temperature changes for Europe on an annual and seasonal scale as well as the tendency of less warming of the RCM results in comparison to the GCMs agree with previous results, e.g. from PRUDENCE (Christensen and Christensen 2007). Furthermore, the projected temperature range (areal mean between 1.1 and $1.5 \mathrm{~K})$ is also narrower than the bias range $(-1$ to $-5 \mathrm{~K}$ for areal means) analysed in Berg et al. (2012). Besides the overall warming, the patterns and magnitudes of the projected changes show larger impact of the GCM and its realisation on the simulation results compared to the RCM, which agrees with previous results (e.g. Déqué et al. 2007).

The changes in annual precipitation over the coarse nest are shown in Fig. 3. The south-north contrast in precipitation changes across Europe, which is described in Christensen et al. (2007), is also indicated by the GCMs applied in this ensemble. The projected changes of the three realisations of ECHAM5 differ in their magnitude, but the overall pattern is similar. For Germany, the different realisations of ECHAM5 produce varying magnitudes of precipitation increase. The CLM downscaling of ECHAM5 indicates a similar pattern of changes in annual precipitation compared to the driving GCM, whereas WRF downscaling tends to a positive annual precipitation change. The climate change signal of CCCma3 is in the same range as that of ECHAM5 R3, but in this case the CLM downscaling intensifies the climate change signals compared to CCCma3. On a seasonal scale precipitation change patterns of the ensemble members for winter are similar to the annual one, but for Northern Europe the projected increases are even larger (not shown). For spring, positive precipitation change signals are also projected for Central and East Europe except for ECHAM5 R3. In summer, the projected decrease of the precipitation signal is more extended in space and magnitude compared to the annual one except for the WRF simulation which produces an increase in mean precipitation from the north-east of the domain into Central Europe. In autumn, a stronger precipitation decrease for the Mediterranean region is simulated compared to the annual results. The transition from positive changes in the north to negative ones in the south moves with the season and varies between the ensemble members. The varying transition and similar precipitation change patterns for Europe were also found in previous studies, e.g. in PRUDENCE (Christensen and Christensen 2007; Déqué et al. 2007). No clear impact of the bias on the projected results could be found.

Overall, the GCM and coarse nest RCM analysis shows that the impact of different GCMs on the simulation results is in the same order of magnitude as the applied initial conditions (realisations) of the GCM. Furthermore, the impact of the RCM on the climate change signal is more dominant for precipitation compared to temperature, which was also concluded for the PRUDENCE simulations (e.g. Déqué et al. 2007). Note, however, that precipitation is simulated differently by the different models as it is a sum of multiple processes within each single model. The end results can therefore differ between a GCM and an RCM due to the parameterisations used, and are not necessarily a result of resolution. CLM and ECHAM5 use a more similar parameterisation of precipitation, i.e. the Tiedtke scheme (Tiedtke 1989), and have similar results, whereas the WRF simulation uses the Kain-Fritsch scheme (Kain 2004), which might explain the different result for summer, as described above. The validation results with ERA40 boundary conditions (Berg et al. 2012) have also shown largest differences in summer precipitation between the two RCMs CLM and WRF. 


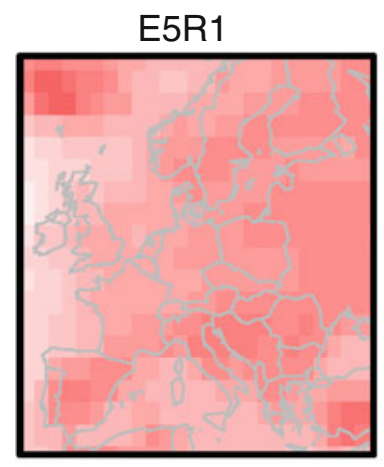

\section{E5R2}

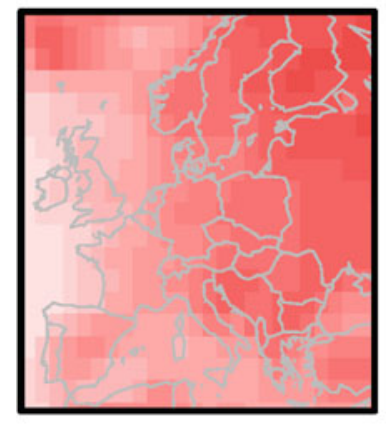

E5R3

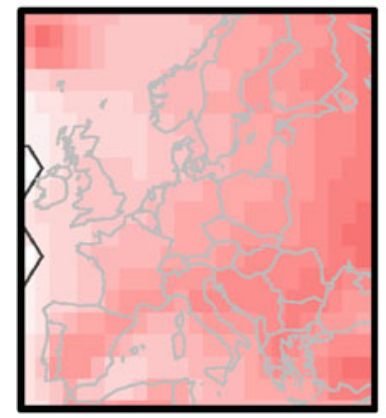

Fig. 2 Projected annual mean temperature change $[\mathrm{K}]$ between 1971-2000 and 2021-2050 for the three ECHAM5 realisations (E5R1-3) and the CCCma3 (C3) GCM (GCM results are marked with a thicker frame), as well as the coarse nest RCM simulations with

\subsection{Fine nest simulations $(7 \mathrm{~km})$}

Changes in the seasonal cycle and annual mean temperature averaged over Germany are listed in Table 1 for all applied GCM-RCM combinations. Statistically significant temperature changes at the $95 \%$ confidence interval are indicated in bold font. All simulation results show a mostly significant warming for all seasons and consequently also on the annual scale. The RCM simulations with ECHAM5 driving data project a warming between 0.8 and $1.3 \mathrm{~K}$. The CLM simulations with CCCma3 driving data are in the same order with a projected warming of $1.1 \mathrm{~K}$. On the seasonal scale, the ECHAM5 R1 driven RCM simulations show similar temperature changes with largest warming in

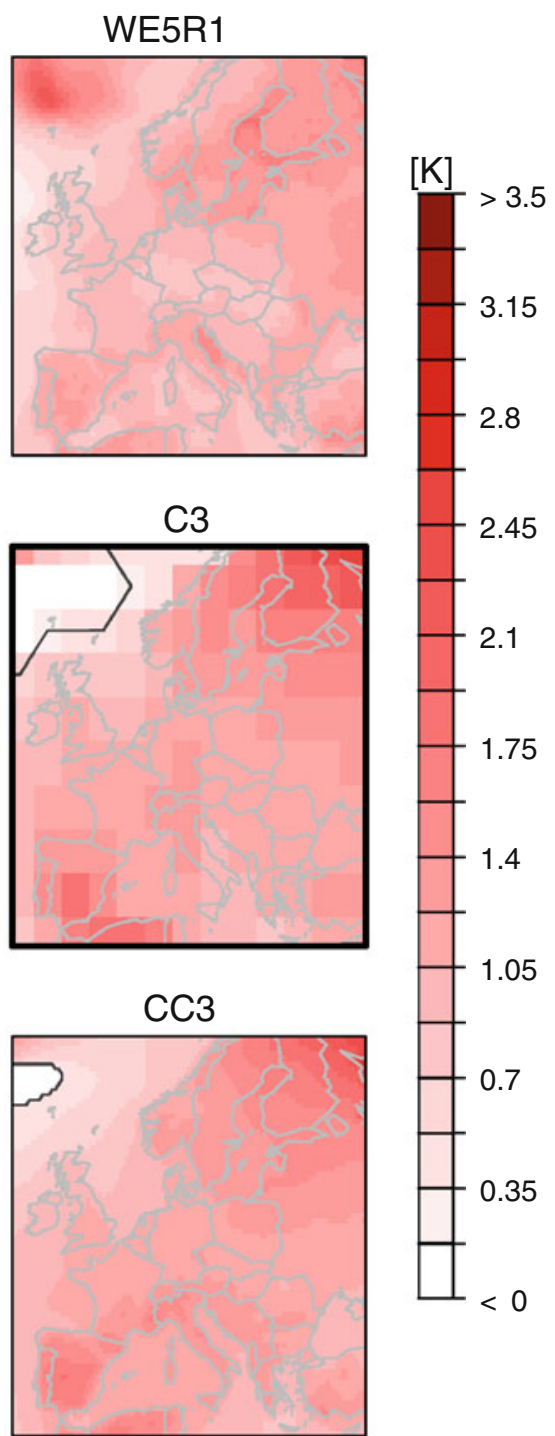

CLM (CLM-E5R1-3 and CLM-C3) and WRF (WRF-E5R1). Contours delineate significant and non-significant regions at the $95 \%$ confidence interval. Note that there are almost no nonsignificant regions in the plots

winter and autumn. The REMO and CLM simulation results are comparable for both realisations of ECHAM5. The CCCma3 driven simulation shows a weaker increase in winter, but otherwise similar results as the ECHAM5 driven simulations. The ensemble mean values project larger warming in winter and autumn compared to spring and summer for Germany. The intra-ensemble standard deviation values indicate higher variability of projected warming of the different ensemble members in winter and spring.

In accordance to the coarse resolution results, the range of the projected climate change signals of the fine resolution ensemble over Germany (see above) is narrower on seasonal and annual scale than the bias range [annual: -2.9 

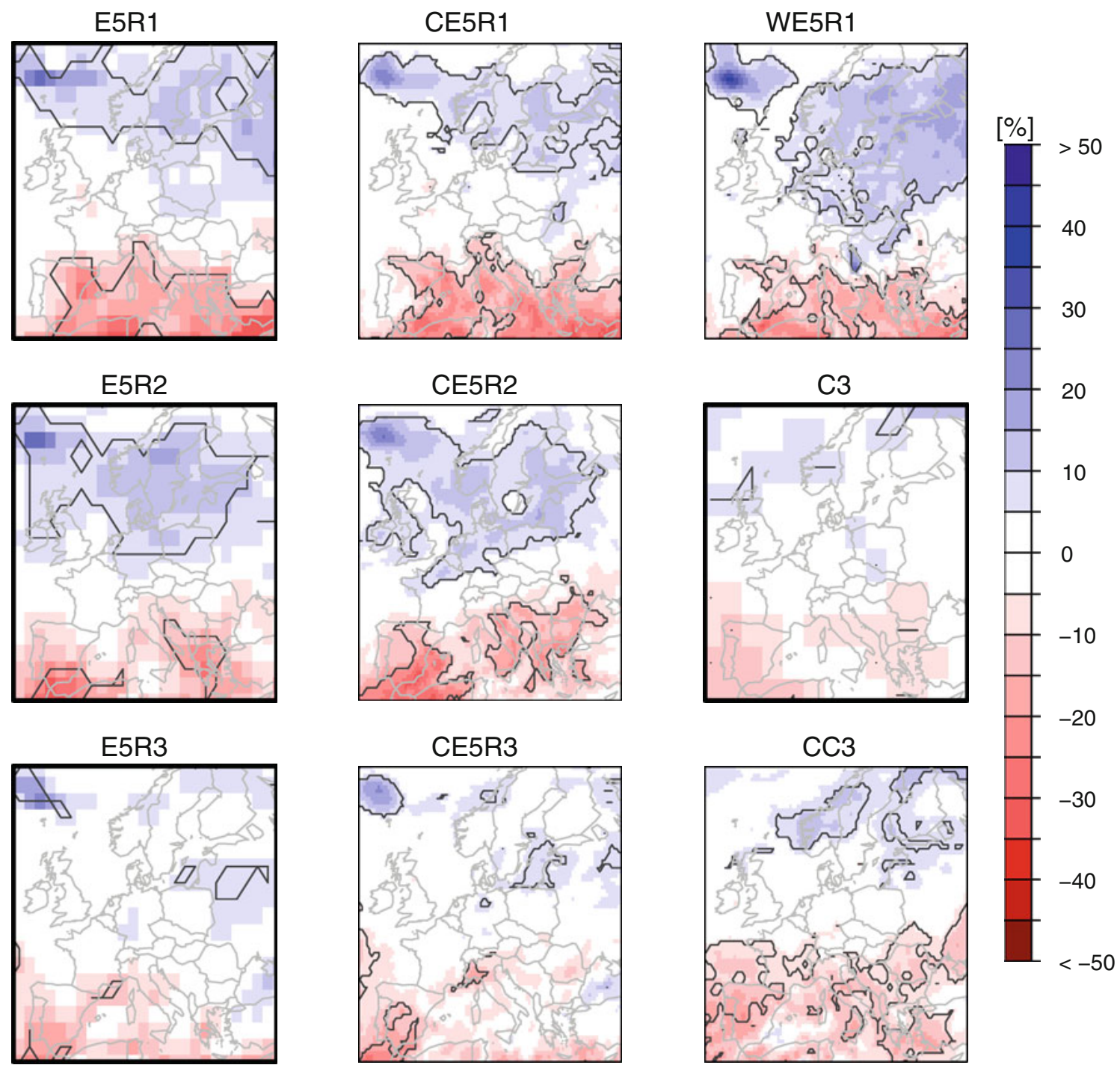

Fig. 3 Projected annual precipitation change [\%] between 1971-2000 and 2021-2050 for the three ECHAM5 realisations (E5R1-3) and the CCCma3 (C3) GCM (GCM results are marked with a thicker frame),

Table 1 Projected fine nest seasonal and annual mean temperature changes [K] averaged over Germany between 1971-2000 and 2021-2050 for the CLM (CLM-E5R1-3 and CLM-C3), REMO as well as the coarse nest RCM simulations with CLM (CLM-E5R1-3 and CLM-C3) and WRF (WRF-E5R1). Contours delineate significant and non-significant regions at the $95 \%$ confidence interval

(REMO-E5R1-2) and WRF (WRF-E5R1) simulations, plus the ensemble mean and intra-ensemble standard deviation

\begin{tabular}{|c|c|c|c|c|c|}
\hline & DJF & MAM & JJA & SON & ANNUAL \\
\hline CLM-E5R1 & 1.4 & 0.2 & 1.1 & 1.5 & 1.0 \\
\hline REMO-E5R1 & 1.6 & 0.2 & 0.9 & 1.2 & 1.0 \\
\hline WRF-E5R1 & 1.6 & 0.3 & 0.6 & 1.4 & 1.0 \\
\hline CLM-E5R2 & 1.9 & 1.0 & 0.7 & 1.5 & 1.3 \\
\hline REMO-E5R2 & 2.0 & 1.0 & 0.9 & 1.6 & 1.3 \\
\hline CLM-E5R3 & 0.7 & 0.7 & 0.8 & 1.0 & 0.8 \\
\hline CLM-C3 & 1.0 & 0.9 & 1.2 & 1.3 & 1.1 \\
\hline ENS mean & 1.4 & 0.6 & 0.9 & 1.4 & 1.1 \\
\hline ENS SD & 0.5 & 0.4 & 0.2 & 0.2 & 0.2 \\
\hline
\end{tabular}

For the ensemble members, numbers in bold font are statistically significant at the $95 \%$ confidence interval 
to $0.5 \mathrm{~K}$ (Berg et al. 2012)] of the ensemble. In general, simulation results using the same GCM (here ECHAM5 R1 or R2) indicate that the RCM impact on the climate changes is relatively small on annual and seasonal averages. In contrast, the selection of the GCM and its initial condition (realisation) results in significantly larger variabilities of projected temperature change for both seasonal and annual averages.

The spatial distribution of annual mean temperature change over Germany of the fine nest is shown in Fig. 4. All RCM simulations project an annual mean warming over Germany, which is significant at the $95 \%$ confidence interval for almost all grid points with a few exceptions in the south for the WRF simulation with ECHAM5 R1 driving data. For the ensemble mean the warming varies spatially between 0.9 and $1.3 \mathrm{~K}$ and an average of $1.1 \mathrm{~K}$ is projected for Germany. Some added small scale details are seen compared to the coarse nest simulations, but generally the patterns are the same. From the ensemble presented here, it is not possible to find any robust differences between the mean warming in different regions of Germany.
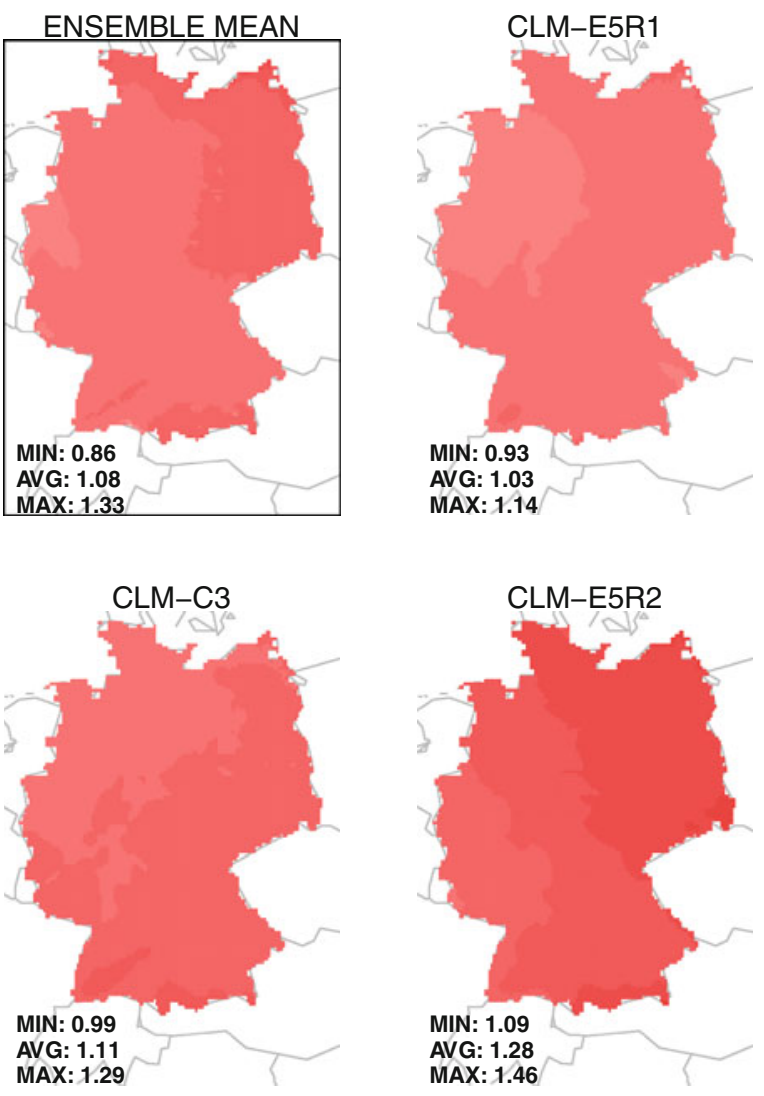

Fig. 4 Projected annual mean temperature change $[\mathrm{K}]$ over Germany between 1971-2000 and 2021-2050 for the CLM (CLM-E5R1-3 and CLM-C3), REMO (REMO-E5R1-2) and WRF (WRF-E5R1) simulations and the ensemble mean. Contours (except for the ensemble
For precipitation, the projected changes on seasonal and annual scales averaged over Germany are listed in Table 2. The seasonal and annual climate change signals of the ensemble members vary in both sign and magnitude. All ECHAM5 driven RCM simulations project an increase of annual precipitation in the range of 2 to $9 \%$. Here, minimum and maximum changes correspond with the same realisation of ECHAM5, which indicates a large impact of the RCM on the climate change signal of precipitation. The CLM simulations with $\mathrm{CCCma3}$ driving data project a decrease of $-2 \%$ of annual precipitation over Germany, which, although not significant, could indicate a larger impact of using different GCMs. In contrast to the temperature change signal, only the ECHAM5 R1 driven WRF simulation and the ECHAM5 R2 driven CLM simulation show significant annual precipitation changes at the $95 \%$ confidence interval. The RCM simulations using ECHAM5 R1 indicate largest precipitation increases in spring, in particular in March with values larger than $20 \%$ (not shown), and autumn. In winter and summer, the climate change signals of the RCM simulations using ECHAM5 R1 vary also in sign. In winter, CLM and WRF project, in contrast to REMO, a precipitation
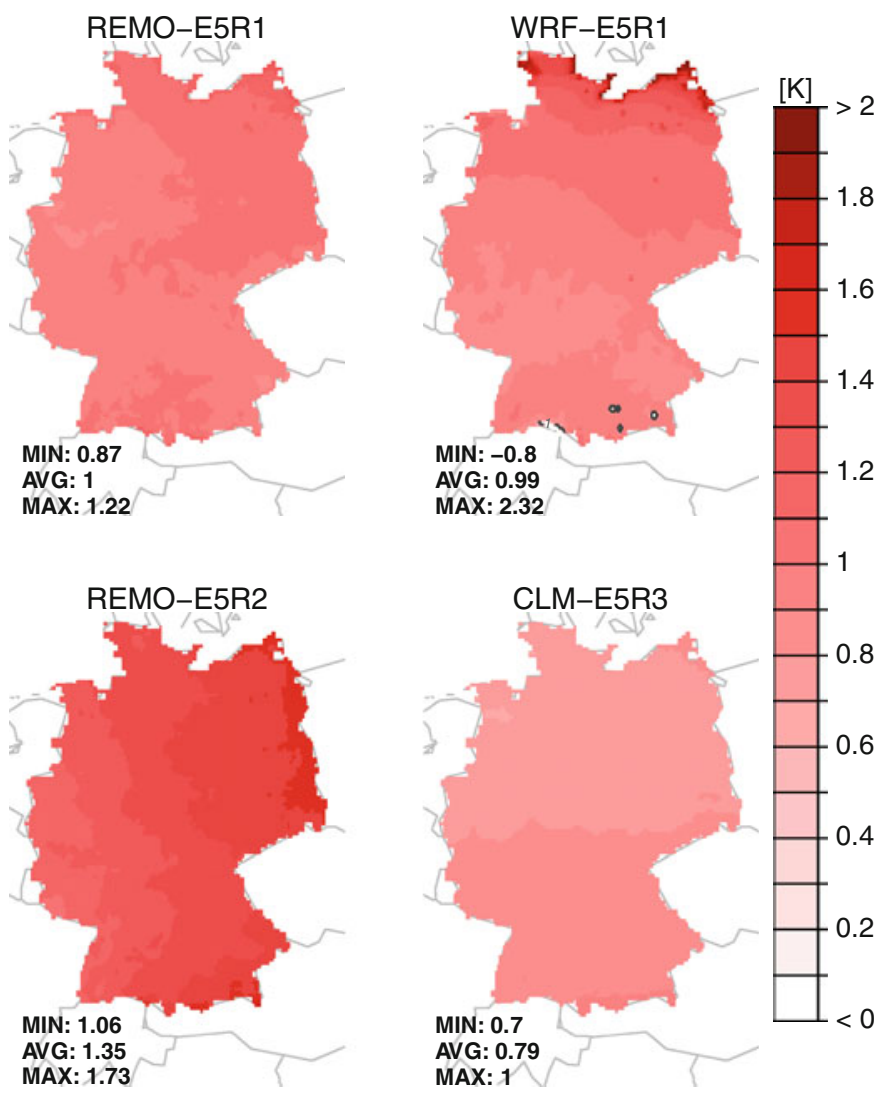

mean) delineate significant and non-significant regions at the $95 \%$ confidence interval. Note that there are almost no non-significant regions in the plots 
increase and in summer CLM and REMO project, in contrast to WRF, a precipitation decrease. Different realisations of the GCM impact the RCM results significantly, which is more distinctive for CLM compared to REMO. The CCCma3 driven CLM simulation projects larger decreases of precipitation in summer compared to the ECHAM5 driven simulations. Most of the seasonal precipitation change signals are non-significant. In spring, two of seven ensemble members, and for the other three seasons only one member, project a significant precipitation change at the $95 \%$ confidence interval. The ensemble means in Table 2 project positive precipitation changes for winter, spring and autumn and a negative change in summer. The intra-ensemble standard deviation values indicate higher variability of the projected precipitation change in winter. Except for the winter season, the RCM simulations with quite different biases $[+30$ to +60\% for annual means (Berg et al. 2012)] project climate change signals which are much closer to each other $(-2$ to $9 \%$ for annual means). The results also confirm the large variability of the magnitude and geographical details of the climate change signals for precipitation for Central Europe as described in Christensen et al. (2007).

The corresponding spatial distributions of annual precipitation change over Germany of the fine nest are shown in Fig. 5. The overlaying contours indicate regions with statistical significance of the climate change signals at the $95 \%$ confidence interval. According to the results of Table 2 the projected annual precipitation changes are significant for large regions of Germany for the ECHAM5 R1 driven WRF simulation and the ECHAM5 R2 driven CLM simulation, and basically no significant regions for the other simulations. No similarities in the mean precipitation change patterns can be seen for the ensemble members. For the ensemble mean, the precipitation change varies spatially between -1 and $7 \%$ and an average of $3 \%$ is projected for Germany.

Table 2 Projected fine nest seasonal and annual precipitation changes [\%] averaged over Germany between 1971-2000 and 2021-2050 for the CLM (CLM-E5R1-3 and CLM-C3), REMO
The comparison of the projected changes for mean temperature and precipitation of the coarse and fine resolution RCM simulations over Germany allows an estimation of the added value of high resolution regional climate simulations. In general, the projected climate change signals of the coarse domain are transferred to the fine resolution without strengthening or weakening the climate change signal. But the higher resolution adds some more detail in the spatial patterns. Furthermore, the climate change signals do not per se show the benefit of highresolution regional climate simulations in bringing high detail in the spatial patterns and added value to the precipitation intensity distributions (see Berg et al. 2012).

Figure 6 shows the projected changes of the probability density function (PDF) of daily precipitation intensities, from here on defined as days with at least $0.1 \mathrm{~mm}$ of precipitation. In general, the intensity distributions of the CLM and WRF models are comparable indicating a decrease of lower precipitation intensities and an increase for higher intensities. Similar changes in the intensity distribution of precipitation were also found in previous studies, e.g. Boberg et al. (2009, 2010). The change point is approximately at $6 \mathrm{~mm} /$ day. WRF produces slightly higher decreases of lower intensities and higher probabilities in particular for moderate intensities in the range of 10-20 mm/day compared to the CLM driven ECHAM5 R1 simulation. Different realisations of the GCM impact the precipitation PDFs somewhat, see e.g. CLM results of ECHAM5 R1 to R3. The precipitation PDFs of the REMO simulations differ significantly in comparison to the CLM and WRF results driven with the same realisations of ECHAM5. In general, smaller changes of the REMO PDF are projected for the low, moderate and higher intensities up to $40 \mathrm{~mm} /$ day, but intensities above $50 \mathrm{~mm}$ occur more frequently within the REMO simulations using ECHAM5 R1. The REMO simulation using ECHAM5 R2 projects an

(REMO-E5R1-2) and WRF (WRF-E5R1) simulations, plus the ensemble mean and intra-ensemble standard deviation

\begin{tabular}{|c|c|c|c|c|c|}
\hline & DJF & MAM & JJA & SON & ANNUAL \\
\hline CLM-E5R1 & 1.3 & 5.0 & -7.9 & 9.3 & 1.9 \\
\hline REMO-E5R1 & -8.1 & 9.1 & -1.6 & 14.9 & 3.6 \\
\hline WRF-E5R1 & 0.4 & 15.9 & 6.2 & 12.9 & 8.8 \\
\hline CLM-E5R2 & 12.3 & 12.8 & -0.6 & 1.8 & 6.6 \\
\hline REMO-E5R2 & -4.2 & 8.7 & 3.7 & 1.4 & 2.4 \\
\hline CLM-E5R3 & 9.6 & -0.7 & -5.0 & 6.0 & 2.5 \\
\hline CLM-C3 & -3.7 & 6.8 & -8.9 & -1.6 & -1.9 \\
\hline ENS mean & 1.1 & 8.2 & -2.0 & 6.4 & 3.4 \\
\hline ENS SD & 7.5 & 5.4 & 5.7 & 6.2 & 3.5 \\
\hline
\end{tabular}

For the ensemble members, numbers in bold font are statistically significant at the $95 \%$ confidence interval 

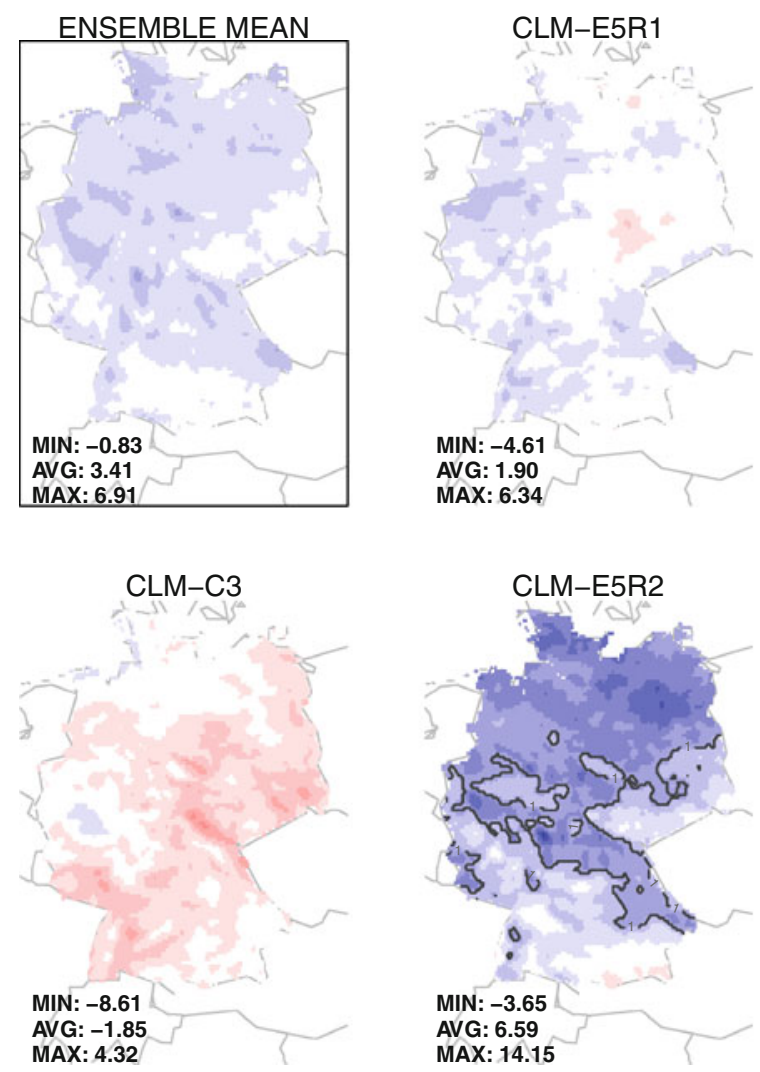

Fig. 5 Projected annual precipitation change [\%] over Germany between 1971-2000 and 2021-2050 for the CLM (CLM-E5R1-3 and CLM-C3), REMO (REMO-E5R1-2) and WRF (WRF-E5R1)

increase of lower intensities, and thereby deviates strongly from the other simulations. The deviation of the REMO model in the projected changes might be a reflection of the bias in the REMO precipitation intensity distribution presented in Berg et al. (2012). When CCCma3 is used as GCM, the projected precipitation PDF differs significantly from the ECHAM5 simulations, however the general trend of a decrease of lower intensities and an increase of higher intensities is also present, but first the magnitude of the projected change is less, and second the change point is shifted to approximately $11 \mathrm{~mm} /$ day. Again, the differences in the $\mathrm{CCCma} 3$ driven simulation could be due to the bias in the precipitation intensity distribution as presented in Berg et al. (2012). The shift of the change point is an interesting result in comparison to Boberg et al. (2009, 2010), where the change point was found to be remarkably similar between different GCM and RCM combinations. Overall, all components of the multi model ensemble, the GCM and its realisation as well as the RCM, impact the projected change of the probability density functions of precipitation significantly.
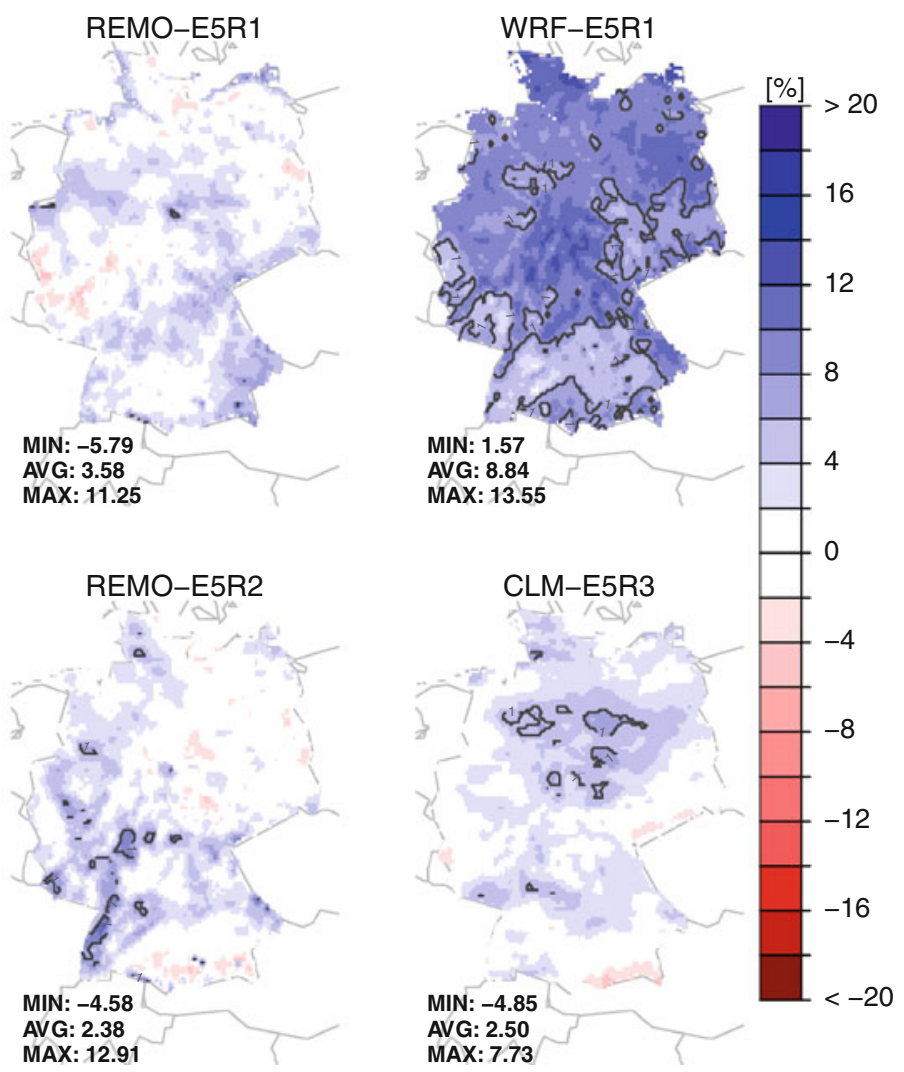

simulations and the ensemble mean. Contours (except for the ensemble mean) delineate significant and non-significant regions at the $95 \%$ confidence interval

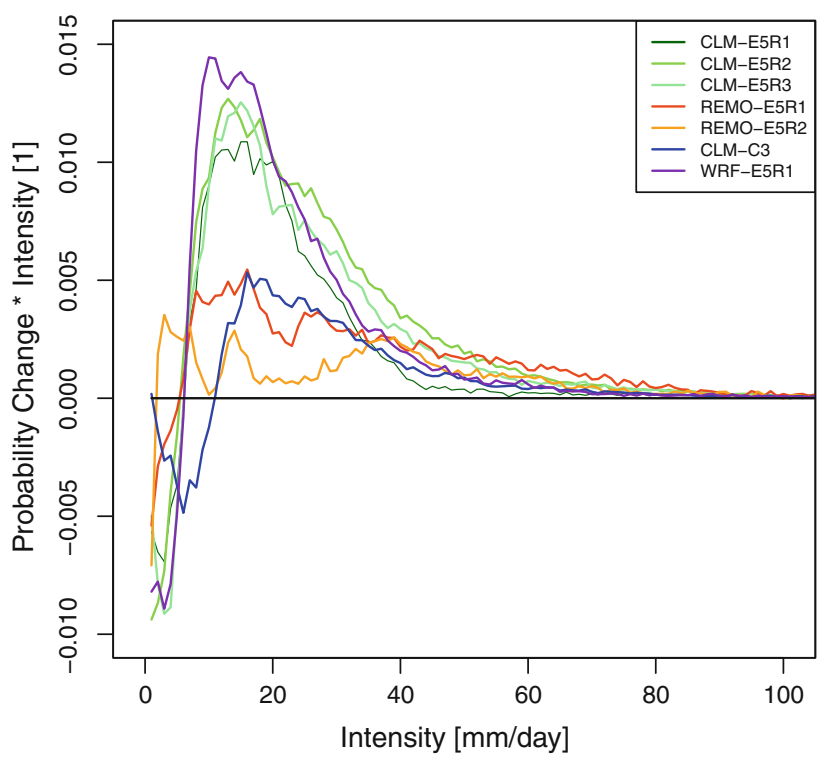

Fig. 6 Projected change of precipitation PDFs multiplied by intensity over Germany between 1971-2000 and 2021-2050 for the CLM (CLM-E5R1-3 and CLM-C3), REMO (REMO-E5R1-2) and WRF (WRF-E5R1) simulations 

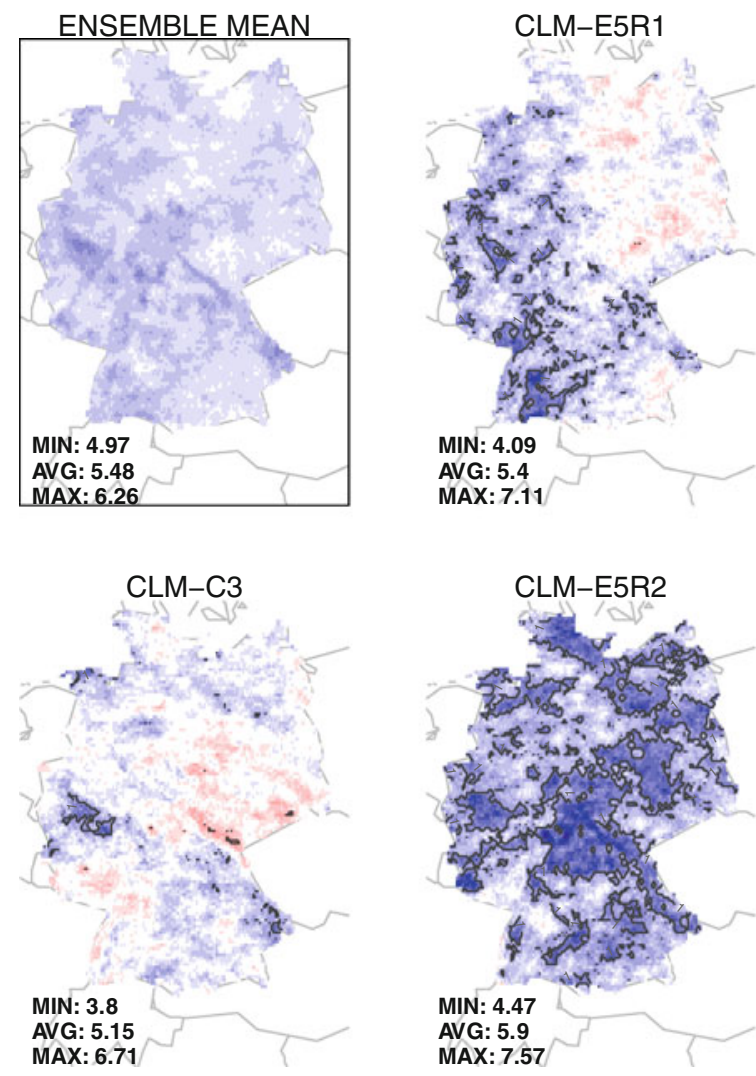

Fig. 7 Projected percentage of wet days in 2021-2050 with precipitation amounts larger than the 95 percentiles of the reference period 1971-2000 for the CLM (CLM-E5R1-3 and CLM-C3), REMO (REMO-E5R1-2) and WRF (WRF-E5R1) simulations and the

Table 3 Projected fine nest seasonal and annual climate change signals for the number of wet days [\%] averaged over Germany between 1971-2000 and 2021-2050 for the CLM (CLM-E5R1-3 and
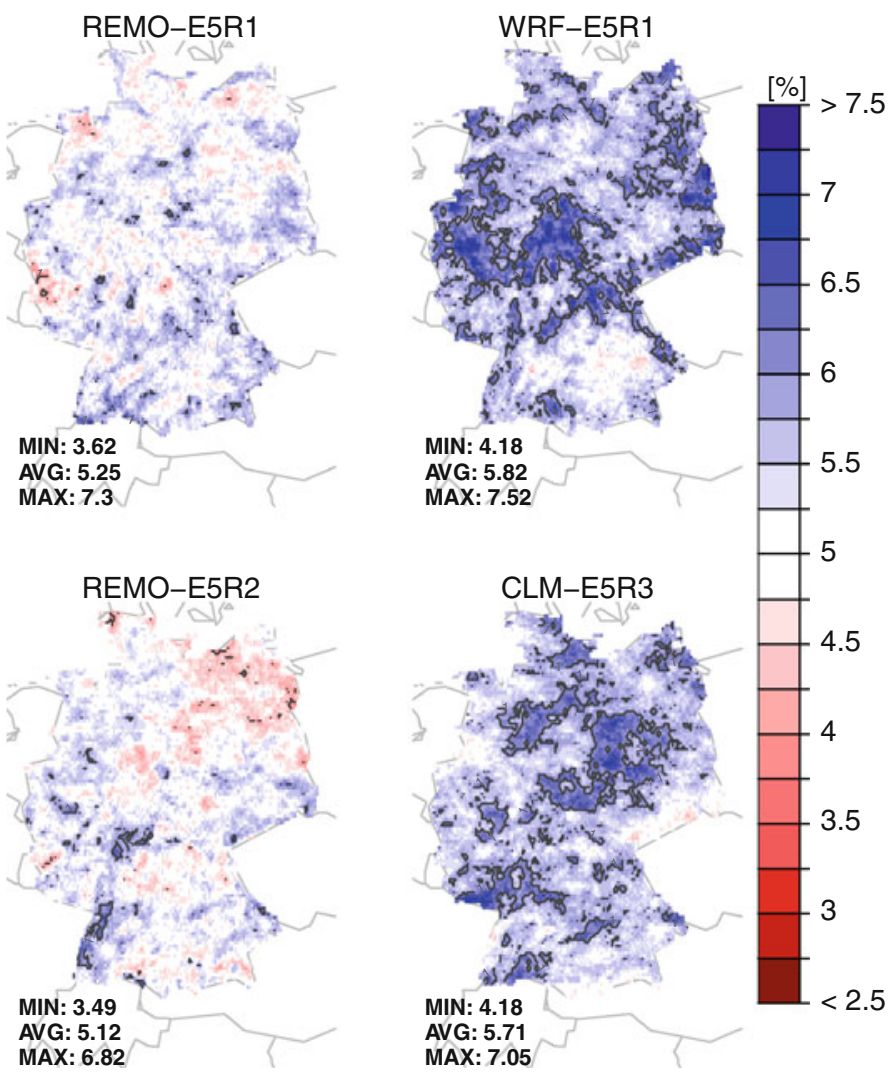

ensemble mean. Values above $5 \%$ indicate an increase and below $5 \%$ a decrease for the future time period. Contours (except for the ensemble mean) delineate significant and non-significant regions at the $95 \%$ confidence interval

CLM-C3), REMO (REMO-E5R1-2) and WRF (WRF-E5R1) simulations, plus the ensemble mean and intra-ensemble standard deviation

\begin{tabular}{|c|c|c|c|c|c|}
\hline & DJF & MAM & JJA & SON & ANNUAL \\
\hline CLM-E5R1 & -1.9 & 5.7 & -10.2 & 0.9 & -1.4 \\
\hline REMO-E5R1 & -6.2 & 7.0 & -4.1 & 5.1 & 0.5 \\
\hline WRF-E5R1 & -1.1 & 10.9 & 1.4 & 6.2 & 4.4 \\
\hline CLM-E5R2 & 5.8 & 6.3 & -0.8 & -7.3 & 1.0 \\
\hline REMO-E5R2 & -0.5 & 6.9 & 0.8 & -4.4 & 0.7 \\
\hline CLM-E5R3 & 6.0 & -5.5 & -7.1 & -1.0 & -1.9 \\
\hline CLM-C3 & -5.0 & 2.6 & -9.8 & -3.3 & -3.9 \\
\hline ENS mean & -0.4 & 4.9 & -4.3 & -0.5 & -0.1 \\
\hline ENS SD & 4.8 & 5.2 & 4.9 & 5.0 & 2.6 \\
\hline
\end{tabular}

For the ensemble members, numbers in bold font are statistically significant at the $95 \%$ confidence interval

The analysis of the probability density functions indicates already in general an increase of higher precipitation intensities for all ensemble members. For the investigation of regions which are projected to be more affected by heavy precipitation events in the future, the spatial distribution of the projected percentage of wet days in
2021-2050 with precipitation amounts larger than the 95 percentile of the reference period 1971-2000 are shown in Fig. 7. Hence, for regions with values larger than $5 \%$ (blue) the 95 percentile value of the present time period occurs more frequently in the future time period. And accordingly for regions with values smaller than $5 \%$ (red) 

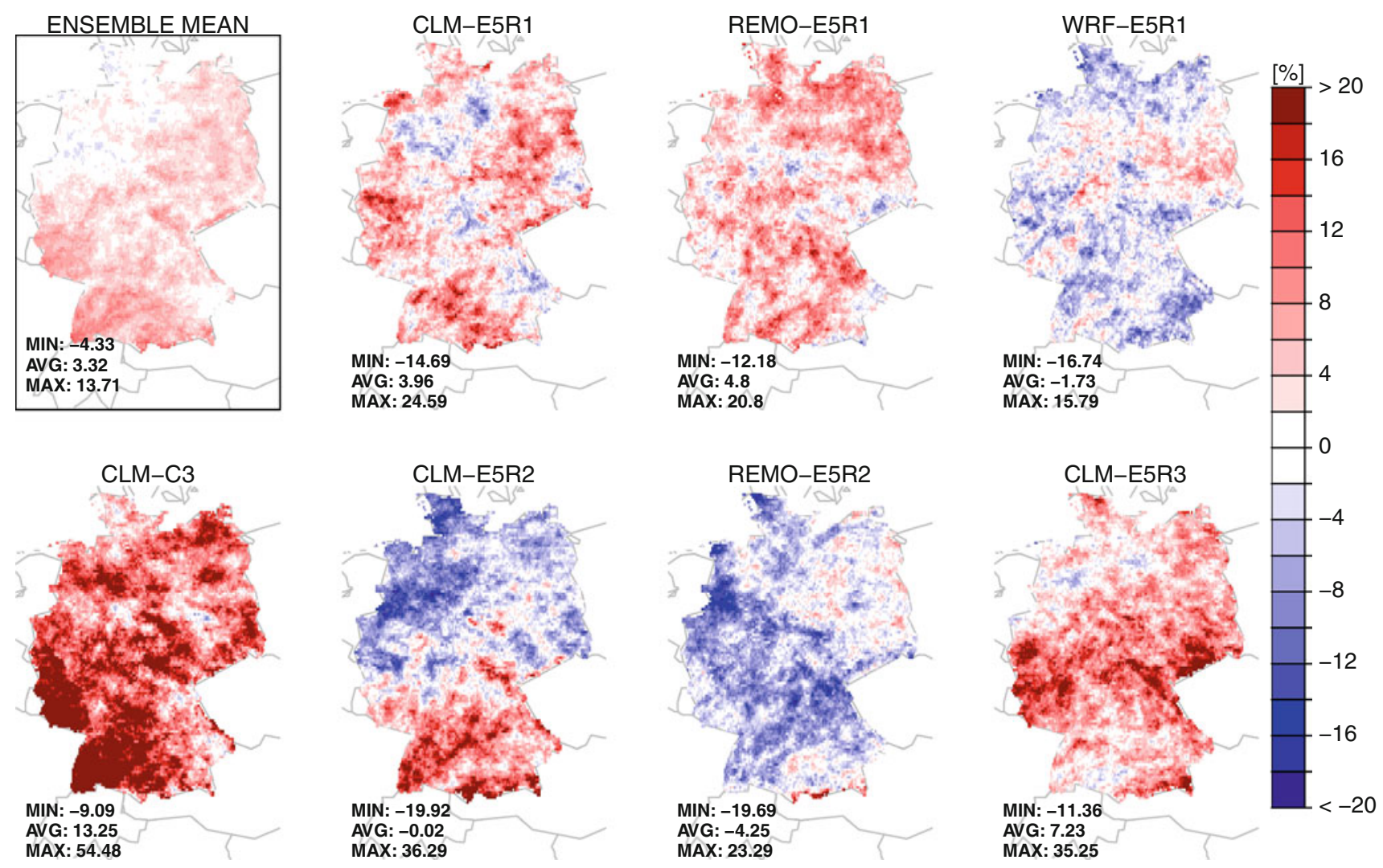

MAX: 35.25

Fig. 8 Projected percentage change of the number of dry periods of more than 5 consecutive days over Germany between 1971-2000 and 2021-2050 for the CLM (CLM-E5R1-3 and CLM-C3), REMO (REMO-E5R1-2) and WRF (WRF-E5R1) simulations and the ensemble mean

the 95 percentile value of the present time period occurs less frequently in the future time period. All RCM simulations project a mean probability increase of the 95 percentile value over Germany. The ensemble mean indicates a probability increase for each grid point in Germany in the range of 0 to $1.3 \%$ units, and an average of $0.5 \%$ units. For the individual ensemble members the projected climate change signal is less clear. The corresponding spatial distributions are very heterogeneous. In particular the REMO simulations also project regions with a probability decrease of the 95 percentile value of the reference period. The CLM and WRF simulations with ECHAM5 driving data show larger regions with significant changes of the 95 percentile value of the present time period. There are, however, no robust patterns between the ensemble members to indicate vulnerable regions. In general, the results indicate that all components of the multi model ensemble (GCM, its realisation, or RCM) impact the probability changes of high precipitation events significantly. Furthermore, it is worth mentioning that the spatial distribution of the projected change of the 95 percentiles differs from the mean annual precipitation change patterns.

For the above analysis of projected climate change in precipitation intensities only wet days are considered. But also the projected differences in the number of wet days or dry days respectively is central to climate change assessments. The spatially averaged values over Germany of the climate change signal of the number of wet days on seasonal and annual scales are listed in Table 3. For the ensemble mean the number of wet days is projected to increase in spring $(5 \%)$ and decrease in summer $(-4 \%)$. Contrary to these projections are the projected increases of the ECHAM5 R1 driven WRF and ECHAM5 R2 driven REMO simulations in summer and the decrease of the ECHAM5 R3 driven CLM simulation in spring. For winter and autumn the climate change signals of the ensemble members compensate to approximately no change. Most of the projected changes on the number of wet days are non-significant. On an annual scale, only the CLM driven CCCma3 simulation shows a significant decrease at the $95 \%$ confidence interval which is mainly due to the reduction of the number of wet days in summer. For the ECHAM5 simulations only one of six members show either a significant increase of the number of wet days in spring or a significant decrease in summer. The results show that, according to the projected mean precipitation changes, all model components impact the projected changes of the number of wet days significantly.

Changes in dry periods are even more important than the number of single dry days for many climate impact studies, 
in particular for agricultural research. Hence, exemplarily the projected percentage change of dry periods of more than 5 consecutive days over Germany are shown in Fig. 8. The projected climate change signals of the ensemble members vary in sign and magnitude. On average over Germany, four members indicate an increase and three a decrease of dry periods for the future time period. Furthermore, the corresponding spatial distributions differ significantly ranging from very patchy to more homogeneous signals. The ensemble mean indicates, except for the north-west part, an increase of the number of dry periods of more than 5 days with an overall average of $3 \%$ for Germany. The time-series of the projected climate change signals are in this case not normally distributed, thus the Student's $t$ test was not applied. In general, the results indicate distinctive variations with respect to the selection of the GCM, its realisations and the RCM.

\section{Summary and conclusions}

The projected climate change signals of a multi model ensemble based on two GCMs (ECHAM5 and CCCma3) and two RCMs (CLM and WRF) were presented. The presented ensemble of regional climate simulations is characterised by its high spatial resolution of $7 \mathrm{~km}$ using a two nest procedure over Europe and Germany and to our knowledge the first long-term regional climate simulation of the RCM WRF for Central Europe. The ensemble was extended by two ECHAM5 realisations downscaled with the RCM REMO at a slightly coarser resolution of $10 \mathrm{~km}$. The simulations were carried out for the present (1971-2000) and future A1B scenario (2021-2050) time periods.

All GCM simulations project a significant warming over Europe on seasonal and annual scales, which is transferred to both nests of the RCMs. For precipitation, all GCM simulations project an increase of annual precipitation in Northern and a decrease in Southern Europe. For both variables, the impact of the two different GCMs on the simulation results is in the same order of magnitude as that due to the applied initial conditions (realisations) of a single GCM. The impact of the RCM on the climate change signal is more dominant for precipitation compared to temperature. In comparison to the GCM climate change signals, the RCM simulation results tend to less warming. The projected temperature and precipitation changes for Europe as well as the different impacts of GCMs and RCMs on the climate change signals agree with previous results (e.g. Christensen et al. 2007; Déqué et al. 2007).

For the fine nest, all simulation results project a significant annual warming over Germany in the range of 0.8 to $1.3 \mathrm{~K}$ and an average of $1.1 \mathrm{~K}$ for the future time period.
The results indicate that most of the variability of the projected temperature change is caused by the GCM and its initial condition (realisation).

For mean precipitation the climate change signal of the fine nest is less clear. The selection of the GCM impacts both the sign and magnitude of the projected change. The selection of the RCM also impacts the climate change signal significantly. Over Germany changes of annual precipitation in the range of -2 to $9 \%$ and an ensemble mean of $3 \%$ are projected. The wet day precipitation intensity distributions project a decrease of lower intensities and an increase of moderate and higher intensities for most ensemble members. But the results show that the projected changes of precipitation intensities vary significantly for the different ensemble members. In contrast to previous studies (Boberg et al. 2009, 2010) also the change point between decreases at low intensities and increases at higher intensities is not model independent.

The climate change signal of the number of wet days projects annual changes in the range of $\pm 4 \%$ for the future time period with an ensemble mean increase in spring of $5 \%$ and a decrease of $-4 \%$ in summer. The projected changes in the number of dry periods of more than 5 consecutive days indicate varying climate change signals for the ensemble members in the range of -4 to $13 \%$. The analysis shows that the range of projected precipitation changes within the ensemble is the result of significant variations in the wet day precipitation intensity distributions as well as in the number of dry days and dry periods of the ensemble members.

The significance tests of the changes in mean temperature show a robust increase for all ensemble members. In contrast, the significance tests of the changes in mean precipitation, heavy precipitation and the number of dry days show that none of them offer robust results. Often only one or two members of the ensemble show significant results, and they often disagree on both the sign and magnitude of the changes (see Tables 2,3). Changes in these variables are thus highly uncertain.

Altogether, the analysis of this ensemble in simulating present climate in part I (Berg et al. 2012) and projected climate changes in this paper (part II) have shown the potential and benefit in bringing high detail in the spatial patterns and the added value in particular to the precipitation distributions even though the simulations suffer from biases in most variables. Despite the different biases of the regional climate models, the range of projected climate change signals for temperature and precipitation are much closer. Subsequent climate impact studies have to be aware of and cope with these uncertainties. Ensemble approaches are recommended to make the variations and uncertainties of the projected climate change signals visible. 
Acknowledgments The authors acknowledge funding from the CEDIM-project "Flood hazard in a changing climate". The RCM simulations were carried out at HLRS at the University of Stuttgart within the project "High resolution climate modelling" for CLM and the project "High resolution regional climate modeling for Germany using WRF" for WRF. We would also extend a great thank you to the CLM and WRF-modeling communities, particularly H.-J. Panitz and J. Werhahn of IMK for help with the RCM simulations. The REMO simulation data was downloaded from the CERA online archive, and our appreciation also to the REMO modeling group at MPI-M in Hamburg. We also appreciate the work of the R Development Core Team (2011) and the developers of CDO, and thank the anonymous reviewers for their valuable comments.

Open Access This article is distributed under the terms of the Creative Commons Attribution License which permits any use, distribution, and reproduction in any medium, provided the original author(s) and the source are credited.

\section{References}

Berg P, Wagner S, Kunstmann H, Schädler G (2012) High resolution regional climate model simulations for Germany: Part I-validation. Clim Dyn (submitted)

Boberg F, Berg P, Thejll P, Gutowski W, Christensen J (2009) Improved confidence in climate change projections of precipitation evaluated using daily statistics from the PRUDENCE ensemble. Clim Dyn 32(7):1097-1106

Boberg F, Berg P, Thejll P, Gutowski W, Christensen J (2010) Improved confidence in climate change projections of precipitation further evaluated using daily statistics from ENSEMBLES models. Clim Dyn 35:1509-1520

Chen F, Dudhia J (2001) Coupling an advanced land surfacehydrology model with the Penn State-NCAR MM5 modeling system. Part I: model implementation and sensitivity. Mon Weather Rev 129(4):569-585

Christensen J, Christensen O (2007) A summary of the PRUDENCE model projections of changes in European climate by the end of this century. Clim Chang 81:7-30

Christensen J, Hewitson B, Busuioc A, Chen A, Gao X, Held R, Jones R, Kolli R, Kwon W, Laprise R et al (2007) Regional climate projections, climate change, 2007: the physical science basis. Contribution of working group I to the fourth assessment report of the Intergovernmental Panel on Climate Change

Déqué M, Rowell D, Lüthi D, Giorgi F, Christensen J, Rockel B, Jacob D, Kjellström E, De Castro M, van den Hurk B (2007) An intercomparison of regional climate simulations for Europe: assessing uncertainties in model projections. Clim Chang 81:53-70

Doms G, Schättler U (2002) A description of the nonhydrostatic regional model LM. Part I: dynamics and numerics. Deutscher Wetterdienst (German Weather Service)

Dudhia J (1989) Numerical study of convection observed during the winter monsoon experiment using a mesoscale two-dimensional model. J Atmos Sci 46(20):3077-3107

Feldmann H, Früh B, Schädler G, Panitz H, Keuler K, Jacob D, Lorenz P (2008) Evaluation of the precipitation for southwestern Germany from high resolution simulations with regional climate models. Meteorol Zeitschrift 17(4):455-465

Frei C, Christensen J, Déqué M, Jacob D, Jones R, Vidale P (2003) Daily precipitation statistics in regional climate models: evaluation and intercomparison for the European Alps. J Geophys Res 108(4124):65-84

Giorgi F (2006) Regional climate modeling: status and perspectives. J Phys IV 139:101-118

Hewitt C (2005) The ENSEMBLES Project. EGU Newslett 13:22-25
Hong S, Lim J (2006) The WRF single-moment 6-class microphysics scheme (WSM6). J Korean Meteor Soc 42(2):129-151

Hong S, Dudhia J, Chen S (2004) A revised approach to ice microphysical processes for the bulk parameterization of clouds and precipitation. Mon Weather Rev 132(1):103-120

Hong S, Noh Y, Dudhia J (2006) A new vertical diffusion package with an explicit treatment of entrainment processes. Mon Weather Rev 134(9):2318-2341

Jacob D, Van den Hurk B, Andrae U, Elgered G, Fortelius C, Graham L, Jackson S, Karstens U, Koèpken C, Lindau R, et al (2001) A comprehensive model inter-comparison study investigating the water budget during the BALTEX-PIDCAP period. Meteorol Atmos Phys 77(1):19-43

Jacob D, Bärring L, Christensen O, Christensen J, de Castro M, Déqué M, Giorgi F, Hagemann S, Hirschi M, Jones R, et al (2007a) An inter-comparison of regional climate models for Europe: model performance in present-day climate. Clim Chang 81:31-52

Jacob D, Göttel H, Kotlarski S, Lorenz P, Sieck K (2007b) Klimaauswirkungen und Anpassung in Deutschland-Phase 1: Erstellung regionaler Klimaszenarien für Deutschland, Abschlussbericht zum UFOPLAN-Vorhaben 20441 138. Umweltbundesamt, DessauRoßlau, ISSN 4359:154. http://www.umweltbundesamt.de

Kain JS (2004) The Kain-Fritsch convective parameterization: an update. J Appl Meteorol 43(1):170-181

Mlawer E, Taubman S, Brown P, Iacono M, Clough S (1997) Radiative transfer for inhomogeneous atmospheres: RRTM, a validated correlated-k model for the longwave. J Geophys Res 102(D14):16663-16682

Morcrette J-J, Smith L, Fourquart Y (1986) Pressure and temperature dependance of the absorption in longwave radiation parameterizations. Beitr Phys Atmos 59:455-469

Nordeng T-E (1994) Extended versions of the convective parametrization scheme at ECMWF and their impact on the mean and transient activity of the model in the tropics. ECMWF Research Department, Technical Momorandum No. 206, European Centre for Medium Range Weather Forecasts, Reading, UK

R Development Core Team (2011) R: a language and environment for statistical computing. R Foundation for Statistical Computing, Vienna. http://www.R-project.org/, ISBN 3-900051-07-0

Reichler T, Kim J (2008) How well do coupled models simulate today's climate. Bull Am Meteorol Soc 89(3):303-311

Ritter B, Geleyn J (1992) A comprehensive radiation scheme for numerical weather prediction models with potential applications in climate simulations. Mon Weather Rev 120(2):303-325

Roeckner E, Baeuml G, Bonventura L, Brokopf R, Esch M, Giorgetta M, Hagemann S, Kirchner I, Kornblueh L, Manzini E, et al (2003) The atmospheric general circulation model ECHAM5. PART I: model description, Report 349, Max Planck Institute for Meteorology, Hamburg, Germany

Schädler G, Berg P, Düthmann D, Feldmann H, Ihringer J, Kunstmann H, Liebert J, Merz B, Ott I, Wagner S (2012) Flood hazard in a changing climate. Tech. rep., CEDIM report Karlsruhe, Germany. http://www. cedim.de/download/Flood_Hazards_in_a_Changing_Climate.pdf

Scinocca J, McFarlane N, Lazare M, Li J, Plummer D (2008) Technical note: the CCCma third generation AGCM and its extension into the middle atmosphere. Atmos Chem Phys 8(23):7055-7074

Skamarock W, Klemp J, Dudhia J, Gill D, Barker D, Duda M, Huang X, Wang W, Powers J (2008) A description of the advanced research WRF version 3. NCAR technical note 475. National Center for Atmospheric Research, Boulder

Sundquist H (1978) A parameterization scheme for non-convective condensation including precipitation including prediction of cloud water content. Q J R Meteorol Soc 104:677-7690

Tiedtke M (1989) A comprehensive mass flux scheme for cumulus parameterization in large-scale models. Mon Weather Rev 117(8):1779-1800 